\title{
LOGÍSTICA DO COMÉRCIO VAREJISTA NA REGIÃO CENTRAL DE RIO DO SUL
}

\author{
LOGISTICS OF RETAIL TRADE IN THE CENTRAL REGION OF RIO DO SUL
}

Frank Dieter Schulze ${ }^{1}$

Marília Soares ${ }^{2}$

\section{RESUMO}

Este documento busca trazer à luz do debate a problemática do deslocamento de cargas na área central de Rio do Sul, cidade considerada de porte médio, segundo o padrão das cidades catarinenses. No decorrer do trabalho ficará demonstrado que as soluções possíveis são propostas já experimentadas e que, uma vez implantadas, exigiriam ajustes e principalmente fiscalização por parte dos agentes envolvidos. Fica claro também que as ações necessárias precisam ser fruto do consenso entre as partes envolvidas em todo o processo de melhoria da mobilidade urbana da cidade. O presente estudo se faz necessário, pois pouco se estuda e discute, na cidade de Rio do Sul, a respeito da mobilidade urbana, tema de fundamental importância, visto que a cidade está crescendo e esse crescimento impacta no comércio, visto que as lojas estão ocupando, não somente os espaços tradicionalmente destinado a elas, como também estão em espaços comerciais comuns, como galerias, prédios comerciais e outras em espaços diferenciados, onde, por muito tempo, eram residências.

Palavras-Chave: Cidade, Mobilidade Urbana, Logística Urbana.

\section{ABSTRACT}

This article tries to bring to light of the debate a problem of the displacement of cargoes in the central area of Rio do Sul, a city considered of medium size, according to the standard of the cities of Santa Catarina. In the course of the work demonstrated that the possible solutions are proposed already tried and that, once implemented, requirements and mainly supervision by the agents involved. It is also clear that the actions are necessary for the development of a process of improvement of urban mobility of the city. The present study is necessary, it is

\footnotetext{
${ }^{1}$ Especialista em Inteligência de Negócios pela UNIDAVI. E-mail: frank.dieter@hotmail.com.

${ }^{2}$ Mestre em Educação: Ensino superior. FURB. E-mail: marisoar@terra.com.br.
} 
considered little studied and discusses, in the city of Rio do Sul, the Respect of urban mobility, The theme of fundamental importance, the view that the city is growing and the growth impacts no trade, since as stores are occupying, not only the spaces traditionally reserved for them, but also in common common spaces, such as galleries, commercial buildings and Others in different spaces, where, for a long time, they were residences.

Keywords: City, Urban Mobility, Urban Logistics.

\section{INTRODUÇÃO}

O transporte urbano de cargas é tema que atualmente ocupa um espaço de destaque uma vez que interfere no dia a dia das cidades dos mais variados portes e, em última anáise, diretamente na vida, e sua qualidade, de cada pessoa. São muitas as formas propostas de intervenção para que o sistema funcione de forma eficaz e eficiente envolvendo todos aqueles que direta ou indiretamente desempenhem algum papel neste teatro que se desenrola diariamente em centros urbanos de menor ou maior dimensão.

Certo é de que para que haja sucesso na concepção e principalmente na implantação das medidas organizadoras do sistema de mobilidade urbana dentro das cidades é que os agentes tenham conhecimento das teorias que tratam do tema e, acima de tudo, a vivência das realidades dos cenários que precisam sofrer intervenções.

Sem estas vivências o risco de serem tomadas medidas inócuas é considerável.

\section{MOBILIDADE URBANA}

A cidade contemporânea tal qual a conhecemos é resultado de um processo evolutivo milenar iniciado a partir dos primeiros ajuntamentos humanos resultantes da transformação do homem que deixava gradativamente de ser nômade para se tornar um indivíduo sedentário.

Esta transformação verifica-se pelo fato de que o homem descobria os meios pelos quais podia prover sua subsistência e de sua prole em locais 
determinados assim como oferecer a segurança e proteção aos agrupamentos tanto do ponto de vista climático com em relação aos seus predadores naturais.

Mas, afinal de contas, o que é a cidade?

Não há definição que se aplique sozinha a todas as suas manifestações nem descrição isolada que cubra todas as suas transformações, desde o núcleo social embrionário até as complexas formas da sua maturidade e a desintegração corporal da sua velhice. As origens da cidade são obscuras, enterrada ou irrecuperavelmente apagada uma grande parte de seu passado, e são difíceis de pensar suas perspectivas futuras. (MUNFORD, 1965, p. 38)

Certo é que as primeiras cidades surgiram entorno do Rio Eufrátes a cerva de 3.500 a.C., como entrepostos comerciais e de defesa militar de terras que guardavam grandes riquezas naturais que transformavam-se em moeda definidora de riqueza e poder.

Neste período de mais de cinco mil e quinhentos anos talvez a humanidade não tenha alcançado o conhecimento à cerca das potencialidades ainda não exploradas das cidades.

Neste contexto de descobertas das cidades através das suas características morfológicas e sociais passou-se a perceber e considerar de forma insofismável a importância do conceito de mobilidade urbana e desta como um elemento fundamental na organização do tecido urbano moderno.

O planejamento urbano das cidades e as transformações morfológicas que estas assumem a cada ciclo de tempo estão associadas a diversos fatores.

A expansão do território urbanizado em geral é decorrente do incremento populacional e do conseqüente aumento da demanda por mais espaços para lazer, habitação, produção e transporte.

A ineficiência de medidas que atendam essas demandas redundam no surgimento de problemas que acabam por se tornarem crônicos.

Dentro deste universo a compreensão do conceito de mobilidade como sendo a "habilidade de movimentar-se, em decorrência de condições físicas e econômicas" (Vasconcellos, 1996, p. 54) ou como "um atributo associado às pessoas e aos bens, correpondente às diferentes respostas dadas por indivíduos e agentes econômicosàs suas necessidades de deslocamento, consideradas as 
dimensões do espaço urbano e a complexidade das atividades nele desenvolvidas" (Vasconcelos, 1996, p. 62).

Seguindo nesta linha de entendimento compreenderemos que a mobilidade de pessoas, bens de consumo e de serviços exerce um impacto direto na organização e funcionamento das cidades acabando por refletir diretamente na qualidade espacial urbana, nas atividades econômicas e sócio-culturais que se desenrolam neste cenário e, em últma instância, na qualidade de vida dos indivíduos que nela habitam.

A mobilidade urbana, segundo o Ministério das Cidades, "é um atributo das cidades e se refere à facilidade de deslocamentode pessoas e bens no espaço urbano. Tais deslocamentos são feitos através de veículos, vias e toda a infraestrutura (vias, calçadas, etc) que possibilitam esse ir e vir cotidiano. É o resultado da interação entre os delocamento de pessoas e bens na cidade".

Neste sentido cabe apresentar algumas definiões importantes dentro do tema da mobilidade urbana e a infraestrutura necessária para sua consecução:

a) Via pública: superfície de propriedade do poder público por onde transitam veículos, pessoas e animais, compreendendo a pista, a calçada, o acostamento, a ilha e o canteiro central.

b) Logradouro: espaço livre destinado pela municipalidade à circulação, parada ou estacionamento de veículos ou à circulação de pedestres, tais como calçadas, parques, áreas de lazer, calçadões, ruas, avenidas, alamedas, etc.

c) Calçada: "parte da via, normalmente segregada e em nível diferente, não destinada à circulação de veículos, reservada ao trânsito de pedestres e, quando possível, a implantação de mobiliário urbano, sinalização, vegetação e outros fins" (Lei Federal no 9.503 - 23/09/1997).

d) Passeio: "parte da calçada ou pista de rolamento, neste último caso, separada por pintura ou elemento físico separador, livre de interferências, destinada à circulação exclusiva de pedestres e, excepcionalmente, de ciclistas (Lei Federal no 9.503 - 23/09/1997)

Vasconcellos (2002) aponta que em países em desenvolvimento as pessoas realizam, em média, dois deslocamentos por dia e que estes deslocamentos acontecem com um maior ou menor grau de conforto que variam 
de acordo com as condições de cada indivíduo cujas implicações são a criação de externalidades como a poluição, congestionamentos com maior ou menor gravidade assim como o consumo de tempo, energia, recursos financeiros e invariavelmente de espaço físico.

O processo de transformação urbana começou a ocorrer notadamente nas últimas cinco ou seis décadas em face dos processos migratórios experimentados em cidades de médio e grande porte em face de uma série de fatores externos dentre os quais destacam-se o esvaziamento do campo e a questão como a falta de oportunidades de desenvolvimento econômico financeiro assim como pela busca de novos patamares de formação formal.

Esse processo trouxe em seu bojo o crescimento desenfreado e desorganizado das cidades com áreas sem as condições de infraestrutura urbana adequada passando a ser ocupadas, além de haver um aumento exponencial de fluxos de trânsito entre os diversos pontos das cidades resultantes também pelo aumento incontrolável do número de veículos de transporte individual em detrimento dos meios de transporte coletivos.

Neste contexto fica fácil compreender que a mobilidade urbana, que tem no seu bojo como um de seus componentes fundamentais o transporte de bens e os deslocamentos para realização de serviços, depente decisivamente de um conjunto de elementos que compõe a infraestrutura indispensável para que aquela se dê de forma ágil e eficiente.

Desta forma, segundo Vaz e Santoro (2005), pensar em mobilidade urbana é, portanto, pensar sobre como organizar os usos e a ocupação da cidade e a melhor forma de garantir o acesso das pessoas e bens ao que a cidade oferece, e não apenas pensar os meios de transporte e trânsito.

A mobilidade urbana, associada à acessibilidade, vem ganhando nos últimos tempos um papel de destaque dentro do campo da arquitetura e do urbanismo das cidades haja vista serem estas áreas do conhecimento humano as responsáveis por criar e construir os espaços urbanos, leia-se infraestrutura, capazes de atender as constantes demandas da sociedade no que concerne ao oferecimento de cidades mais eficientes tanto em termo de segurança e conforto com de sustentabilidade.

Neste contexto, os planos diretores regionais e municipais desempenham 
um papel crucial na formulação de políticas e mecanismos legais capazes de chamar para um esforço conjunto a esfera privada, a pública e a comunidade.

Todos estes fatores vão nos conduzir à um quadro em que cidades de grande porte e mesmo as consideradas de médio ou pequeno vivenciem atualmente problemas de congestionamentos e de falta de espaços públicos destinados ao estacionamento de automóveis e veículos de cargas e de prestação de serviços.

\section{TRANSPORTE URBANO DE CARGAS}

Pode-se definir transporte de cargas, em geral, como sendo o tráfego de cargas, completas ou fracionadas, embaladas ou não, de um ponto à outro, e que dependendo de sua natureza, emprega veículos e equipamentos próprios para cada tipo de produto transportado.

O transporte de cargas em especial nos centros urbanos é um elemento fundamental em se tratando de mobilidade urbana pois desempenha um papel estratégico no desenvolvimento econômico e soical das cidades.

O deslocamento de cargas é proporcionalmente maior em um país, estado, região ou cidade quanto maior for o grau de desenvolvimento das atividades agrícolas, industriais, comerciais, educacionais ou públicas. Paradoxalmente, este grau elevado de trocas exercerá também maior pressão sobre os meios e a infraestrutura necessária para a realização dos deslocamentos de cargas e realização de serviços com maior agilidade e eficiência.

O processo de globalização que se verifica nas últimas duas ou três décadas reforçou a necessidade de melhoria considerável da logística para satisfação do aumento das demandas ligadas ao deslocamento e entrega de cargas e ecomendas independentemente do porte das cidades.

\footnotetext{
Os serviços de transporte, suas características, localizações e capacidades são diretamente influenciados pelas características do espaço geográfico no qual se inserem e, conseqüentemente, exercem influência direta nas modificações pelas quais este espaço será submetido ao longo do tempo (BOARETO, 2003, p. 11).
}

Percebe-se que as condições geográficas e morfológicas das cidades tem 
uma influência fundamental na eficiência das soluções necessárias para a criação da infraestrutura adequada para o funcionamento do sistema de transportes desde o deslocamento das matérias primas que abastecerão a indústria até o entrega do produto acadado nas mãos do consumidor final.

Ao verificar-se a atenção dispensada ao estudo da logística de transporte tanto em nível geral entre os pontos de produção e de distribuição, como no âmbito urbano de entrega nos pontos finais de recepção, percebe-se que o tema é relativamente novo.

Somente nas últimas décadas despertou-se para a premência na busca de soluções que atendessem às exigências do público consumidor associadas às questões de mobilidade urbana e de sustentabilidade com a superação de problemas com a falta de espaços próprios para estacionamentos de veículos empregados no transporte de cargas urbanas.

O transporte de urbano de cargas é fundamental para a vida em sociedade visto que somente no Brasil, de acordo com pesquisas do IBGE (2010), $84,36 \%$ da população vive nas cidades e toda a atividade econômica pressupõe em algum momento o transporte .

Desta forma, o transporte de cargas eficiente tem papel significativo na competitividade de uma dada área urbana interferindo na econômia da região servindo à indústria e às atividades de comércio, que são essenciais à geração de riqueza.

Mudanças ocorridas nas relações comerciais entre empresas, bem como nos padrões de consumo da sociedade, tendem a aumentar cada vez mais a circulação de veículos de cargas nas áreas urbanas. Nas relações empresariais, destacam-se as mudanças visando melhorias na eficiência logística, redução de estoques e ao rápido atendimento das necessidades dos clientes (através da aplicação de conceitos como justin-time de fabricação, EDI's - Eletronic Data Interchange, Cross-Docking e Milk Run). Quanto ao comportamento dos consumidores, visualiza-se o fortalecimento do e-commerce (comércio eletrônico), que no Brasil, de acordo com daods da e-Bit (2012) em 2011 registrou um crescimento de $26 \%$ em relação ao ano de 2010, tendo movimentado US\$ 53,7 milhões de compras realizadas pela internet (VILELA et all, 2014, p. 02).

Diante deste quadro é indispensável a busca de soluções que assegurem a melhoria da logística de transporte urbano de mercadorias em face da perspectiva 
no incremento do número de transações comerciais tanto por meio físico como por meio eletrônico mas que, inveriavelmente, implicarão no transporte de algum tipo de carga.

O transporte de cargas representava em 2007 (Brasil) entre 20 e 30\% do tráfego rodoviário. Contudo, este volume respondia pela emissão de 16 a 50\% dos poluentes, números estes que que tendem à aumentar em não havendo a ampliação de medidas mitigadoras.

A European Comission for Energy, Environmet and Sustainable Development (2005) informa que os impactos do transporte de cargas com congestionamentos, danos à malha viária, pavimento e sinalização, acidentes de trânsito, prejuízos à circulação dos pedestres, ciclistas e veículos de transporte coletivo, poluição ambiental, visual e sonora e conseqüente aumento de custos de distribuição que refletem no custo final dos produtos podem ser estruturados por cinco variáveis de um círculo vicioso:

1. Congestionamentos

2. Emissões

3. Ruídos

4. Dano à Infraestrutura

5. Ausência/Diminuição da Segurança

É importante destacar, entretanto, que as variáveis listadas acima e que segundo a ECEESD impactam na qualidade da mobilidade urbana, não são de forma alguma causadas exclusivamente pelo transporte de cargas urbanas mas sim produzidas por todos os atores presentes no cenário urbano.

Em razão desta perspectiva e da continua perda da qualidade de vida não só nos grandes aglomerados urbanos mas também em centros considerados médios ou mesmo de pequeno porte, é imperioso que haja cada vez maior atenção no planejamento dos processos que envolvem o deslocamento e entrega de cargas nas regiões urbanas como forma de minimizar os efeitos diretos e indiretos dessas rotinas.

Embora todo o processo de transporte de cargas urbanas envolva uma série de etapas, o tempo das viagens dos veículos carregados entre os centros de distribuição até o recebedor do produto (cliente) e o tempo de procura de vaga 
própria de parada para a coleta e/ou entrega dos produtos constituem naquelas que acabam por contribuir decisivamente na formação de congestionamentos e na conseqüente imobilidade urbana, principalmente nas áreas centrais de nossas cidades.

Segundo Sinay et al (2003), "em estudo desenvolvido por pesquisadores da Universidade de Westminster, Inglaterra, para as cidades de Londres e Norwick, os autores chegaram à conclusão que enquanto os motoristas dos veículos de carga despendem $10 \%$ do tempo total da viagem nos percursos de ida e volta, $1 \%$ em contatos com os clientte e $2 \%$ em congestionamentos diversos, a moior parte, ou seja $87 \%$ do tempo total é gasto procurando local para estacionamento do veículo e providenciando a coleta ou a entrega da carga.

Esta constatação demonstra a necessidade de haver um trabalho conjunto envolvendo todos os partícipes do processo que são os agentes públicos, responsáveis pelo planejamento urbano de forma geral e aqueles responsáveis especificamente pela organização, controle e fiscalização do trânsito nas cidades, os fabricantes dos produtos ou serviços que geram efetivamente os produtos que terão que ser transportados, os comerciantes responsáveis pela venta destes produtos, as transportadores e operadoras logísticas em suas diversas modalidades, os fabricantes de veículos e equipamentos empregados na logística de transporte destas cargas e fianlmente a sociedade representada em última instância pelo público consumidor.

Encontrar soluções de mobilidade que atendam aos interesses específicos de cada um destes agentes, que em muitos casos podem apresentar-se antagônicos, representa encontrar o ponto de equilíbrio no jogo da dia a dia das cidades e que significa promover a manutenção e mesmo a recuperação de determinados atributos que qualificam positivamente a vida nos centros urbanos.

\section{COMÉRCIO VAREJISTA DA CIDADE DE RIO DO SUL}

O município de Rio do Sul situa-se em Santa Catarina, na rigião do Alto Vale do Itajaí, constituindo-se no maior município em termos de população e de economia. Segundo o último senso do IBGE de 2010, sua população soma 66.255 habitantes, apresentando uma densidade de $253,88 \mathrm{hab} / \mathrm{km}^{2}$, haja vista que possui 
um território de 260,97 km².

Rio do Sul ocupa a 18 posição no ranking das economias do estado. Este dado demonstra que Rio do Sul ocupa um papel de destaque no contexto estadual e de de liderança regional em termo de força economica. Constitui-se em referência para os demais municípios da região, que é eminientemente agrícola, por apresentar uma economia bastante diversificada. Esta diversificação do parque industrial, da rede de comércio varejista e de prestadores de serviços à torna ponto de atração para todos os outros 27 municípios que compõe a reigião do Alto Vale.

Geograficamente, Rio do Sul apresenta um território bastante acidentado e pelo qual correm inúmeros leitos de riachos, ribeirões e rios. É no centro que de Rio do Sul que nasce o Rio Itajaí Açu a partir da junção do Rio Itajaí do Su e do Itajaí do Oeste. A patir dai passa a cortar o Médio Vale do Itajaí e a região denominada de Foz do Rio Itajaí Açu, onde desagua no Oceano Atlântico, estando sua foz às margens do municípios de Navegantes e Itajaí.

Esta condição da cidade estar situada em um pequeno vale cortado por um Rio que recebe a contribuição de um grande volume de água trazidas por seus afluentes representa um acondicionante extremamente complexa no desenvolvimento urbano do município e, em especial, da cidade.

Planejar a infraestrutura do município e especificamente a infraestrutura da área central da cidade sempre representou um desafio, mesmo porque somente passou a ser foco dos gestores municipais a partir da década de 1970. Até então as iniciativas neste sentido foram rigorosamente modestas.

Neste contexto a cidade foi desenvolvendo suas atividades comercial e de prestação de serviços em uma poligonal bastante exígua composta por um número restrito de pouco mais de 10 ou 12 quadras.

Segundo o IBGE, no ano de 2004, os estabelecimento comerciais no município de Rio do Sul totalizavam 1.204 unidades e, embora tenham ocorrido algumas transformações urbanas consideráveis em termos de morgologia urbana, a área central da cidade continua à exercer um atrativo forte principalmente em relação os estabelecimentos comerciais ligados ao varejo de roupas e confecções, móveis e eletro-eletrônicos e prestadores de serviços bancários.

É perceptível, entretanto, que atividades como prestadores de serviços e profissionais liberais nas áreas da saúde, direito, engenharia e arquitetura, 
gastronomia e mesmo lazer tem buscado localizar seus estabelecimentos em áreas periféricas ao núcleo urbano central da cidade principalmente em razão das dificuldades de mobilidade no centro da cidade.

A concentração de atividades de algumas linhas de comércio varejista e alguns tipos de prestadores de serviços na área central de Rio do Sul tem sido responsável pela geração do aumento da demanda de cliente que buscam tais atividades em razão do crescimento dos fluxos tanto locais como de contigentes de outras cidades do Alto Vale que cada vez mais acorrem à Rio do Sul.

Embora constatem-se movimentos do comércio e dos prestadores de serviços tanto em oferecer maiores diversidades ao público nas cidades satélites de Rio do Sul assim como nos bairros da capital do Alto Vale, é evidente o aumento dos fluxos de trânsito de automóveis como de transporte de mercadorias na área central da cidade.

Estes incrementos redudam cada vez mais no aumento de viagens e do número de automóveis de passeio e de veículos de transporte de cargas das cidades vizinhas ao centro de Rio do Sul e dos bairros periféricos do município à este centro da cidade.

Neste quadro, naturalmente, administração municipal tem tido um papel importante na fomulação de medidas tanto no âmbito do planejamento urbano através da adoção, a partir de 1.995, do Plano Diretor do Município e sua constante atualização, assim como de medidas adotadas diretamente no sistema viário. Essas medidas buscam encontrar soluções que ofereçam maior fluidez e segurança ao tráfego tanto de pedestres, ciclistas como de automóveis e veículos de carga.

Considerando-se que até a entrada em vigor do Plano Diretor do município e da vigência da Lei 2.030, que disciplinava a elaboração de projetos e execução de obras no mununicípio, havia uma grande resistência na aceitação da necesssidade de previsão de vagas de estacionamento e de garagens no interior dos lotes ou das edificaçõs. Atualmente a comunidade vê de forma muito positiva essas exigências, inclusive em muitos casos, projetando vagas acima do mínimo exigido o que nos leva à concluir que tem havido avanços bastante significativos na conciência em relação aos problemas de mobilidade urbana.

Da mesma forma a implantação de uma considerável malha de ciclovias e 
ciclo faixas nos principais eixos de circulação viária do município e, em particular, na área central da cidade tem estimulado a opção do transporte individual por bicicleta em substituição ao automóvel.

Outra medida importante visando disciplinar o uso do espaço público para estacionamento de veículos foi a implantação do estacionameto controlado, denominado de zona azul, na décda de 1.990, que procurou estimular a rotatividade dos veículos no uso de vagas.

Porém, mesmo diante da constatnte atuação dos setores técnicos da Prefeitura Municipal na formulação de mecanismos visando destravar e agilizar os fluxos de trânsito nas áreas mais congestionadas da cidade, constata-se que há ainda dificuldades que precisam ser superadas.

\section{METODOLOGIA DA PESQUISA}

Este artigo foi escrito à partir de uma pesquisa de caráter qualitativo, na modalidade de pesquisa exploratória documental e descritiva. A pesquisa exploratória é utilizada quando não há conhecimento suficiente sobre o assunto, o que se faz necessário neste estudo sobre o A Logística do Comércio Varejista na àrea Central de Rio do Sul, já que há poucos trabalhos acadêmicos desenvolvidos no contexto regional.

A coleta de dados se pautou tanto pelo levantamento de dados secundários como pela realização de entrevista.

As entrevistas foram realizadas com as pessoas responsáveis pelos seguintes órgãos, diretamente relacionados ao tema em pauta, sendo eles: o Depatamento de Trânsito da Prefeitura Municipal de Rio do Sul; a Secretaria de Desenvolvimento Econômico da Prefeitura Municipal de Rio do Sul; o Sindicomércio (Sindicato do Comércio Varejista do Alto Vale do Itajaí) e a CDL ( Câmara de Dirigentes Lojista de Rio do Sul). Cada um desses órgãos foi representado por um profissional do mesmo ou uma empresa associada, como no caso do Sindicomércio e CDL.

Obviamente que, para fundamentar o presente artigo, a pesquisa bibliográfica se fez presente e as informações e dados foram obtidos através de livros, artigos, pesquisas na internet. 
Conforme definição de Gil (2002, p.44) "pesquisa bibliográfica é desenvolvida com base em material já elaborado, constituído principalmente de livros e artigos científicos". O material bibliográfico utilizado no estudo foram livros e publicações de artigos e livros online.

Para Marconi e Lakatos (2010), uma pesquisa bibliográfica engloba toda a bibliografia que já foi publicada em relação ao tema escolhido para o devido trabalho, podendo ser de jornais, revistas, livros, artigos, monografias, e ainda rádio, televisão e outros. O importante é que o pesquisador possa estar em contato com a maior quantidade possível de material para que este possa desenvolver seu trabalho ou sua pesquisa, tendo assim resultados satisfatórios.

A pesquisa bibliográfica trará ao pesquisador tanto a base para sua pesquisa quanto novos conhecimentos e conceitos, onde o próprio pesquisador poderá assim chegar a novas conclusões sobre o tema por ele escolhido.

\section{RESULTADOS DA PESQUISA}

A abordagem do tema da mobilidade urbana e do transporte urbano de cargas é relativamente novo dentro dos meios científicos e das academias. Mesmo assim, pode-se acessar à um conjunto considerável de trabalhos científicos e pesquisas de campo que tratam do assuntoe apresentam números que servem de base para novos trabalhos.

Tratando-se, entretanto, de ciddes de pequeno ou médio postes a disponibilidade de dados é bastante restritiva principalmente em se falando de números estatísticos.

A cidade de Rio do Sul não é uma excessão. Quando buscamos dados que pudessem subsidiar nosso estudo sobre a mobilidade do transporte de cargas na área central da cidade constatamos a ausência de informações atinentes ao tema.

Diante desta constatação dicidimos realizar a aplicação de um formulário com perguntas relativas especificamente à disponibilidade de vagas de estacionamento para veículos de carga e descarga na área central.

A aplicação se daria envolvendo alguns atores que tem papel no cenário do transporte de cargas no centro de Rio do Sul. 
Estes atores seriam:

1. Departamento de Trânsito da Prefeitura Municipal de Rio do Sul.

2. Secretaria de Desenvolvimento Econômico da Prefeitura Municipal de Rio do Sul.

3. Sindicomércio - Sindicato do Comércio Varejista do Alto Vale do Itajaí.

4. CDL - Câmara de Dirigentes Lojista de Rio do Sul5. Comércio Varejista de diversos ramos de atuação localizadas no polígono central da cidade.

Uma vez definido o cojunto de entrevistado que interessava ser ouvido em relação ao tema do transporte de cargas no centro de Rio do Sul, foram definidas as perguntas mais adequadas para o levantamento de dados que foram as seguintes:

1. Vocês recebem reclamações dos empresários sobre a dificuldade na entrega e retirada de materiais na região do estudo?

2. Vocês recebem reclamações dos consumidores sobre a dificuldades na entrega ou retirada de materiais na região do estudo?

3. Há horários regulamentados para a realização do abastecimento e retirada de mercadorias dos estabelecimentos comerciais?

4. Os horários atendem às necessidades de lojistas e do público consumidor?

O questionário (apêndice 1), é composto com perguntas abertas e fechadas, tendo sido aplicado ao público-alvo da pesquisa, nos dias 10 e 12 de abril de 2017 e as respostas foram dadas pelos seguintes entrevistados:

1. Departamento de Trânsito da Prefeitura Municipal

2. Sindicomércio

3. Padaria e Confeitaria Casa do Pão Centro

4. Loja Multisom

5. Drogaria e Farmácia Gemballa

A análise das resposta dadas apontam que há uma desconexão entre o setor público e o privado. Enquanto o Departamento de Trânsito da Prefeitura afirma que não recebe queixas em relação às dificuldades de estacionamento de veículos para carga e descarga, o Sindicomércio e os estabelecimentos do 
Comércio Varejista concordam que há queixas recebidas do público que se vale destas vagas para procederem as operações de retirada ou entrega de mercadorias.

Outro ponto destacado pelos entrevistados é o de que não há qualquer tipo de fiscalização por parte do setor público, tanto do Departamento de Trânsito como da Guarda Municipal, quanto ao uso das pouquíssimas vagas disponíveis para o estacionamento dos veículos que realizam o procedimento de coleta e entrega de cargas no centro de Rio do Sul.

No tocante ao número de vagas destinadas ao estacionamento de veículos de carga e a existência da regulamentação de horários específicos para realização das operações, há unanimidade entre os entrevistados de que o número é insuficiente em relação as vagas disponíveis.

Entretanto, no que diz respeito ao estabelecimento de horários a Prefeitura Municipal informa que a Lei Municipal no 5.796/16 autorizou o poder público municipal a definir locais e estabelecer critérios para operações de carga e descarga.

Ocorre, porém, que a lei até o momento não foi regulamentada o que inviabiliza sua aplicação.

Percebe-se, entretanto, que a medida não é conhecida pelos representantes do comérico varejista e que haveria conflito caso houvesse a implementação de horários não coincidentes com o horário de funcionamento dos estabelecimentos comerciais.

\section{CONSIDERAÇÕES FINAIS}

Examinando detidamente as fundamentações teóricas do tema da mobilidade urbana e, em especial, a questão do transporte de cargas nos centros urbanos aliado à análise das informações específicas sobre o quadro na cidade de Rio do Sul, pode-se compreender que ao longo de um período de tempo foram adotadas medidas regulamentadoras que amenizaram os efeitos do aumento da demanda por vagas de estacionamento para automóveis também veículos de carga e descarga.

Essas medidas monstraram-se eficientes, porém não suficientes. 
Atualmente verifica-se a necessidade da implementação de medidas que avancem ainda mais sobre a problemática de regulamentação do transporte de cargas na cidade de Rio do Sul com o consequente aumento da fiscalização das medidas regulamentadoras adotadas.

Constata-se que a adoção de medidas nesse sentido são variadas e possíveis havendo, entretanto, um amplo entendimento entre os agentes públicos e privados envolvidos tendo sempre como norteador das discussões e adoção de medidas os interesses da sociedade civil em geral sem a proteção de interesses individuais em particular.

Assim, importante se faz pensar em ações futuras no que diz respeito as regras e leis municipais que tratam da mobilidade urbana, visto o crescimento vertiginoso das cidades, sem que haja uma revisão frequente do plano diretor, as construções sem um estudo adequado do impacto de vizinhança, a liberação desenfreada de obras em espaços destinados a residências e uma falta total de um estudo minucioso a respeito de como acompanhar o crescimento socioeconômico das cidades que também permita manter a adequada mobilidade urbana.

\section{REFERÊNCIAS}

BRASIL. Ministério das Cidades. 2007. Caderno PlanMob: para orientação aos órgãos gestores municipais na elaboração dos Planos Diretores de Mobilidade Urban. Brasilia.

Boareto, R.A. 2003. Mobilidade Urbana Sustentável. Revista dos Transportes Públicos, São Paulo. N. 100.

GIL, Antonio Carlos. Como elaborar projetos de pesquisa. 5.ed. São Paulo: Atlas, 2002.

LAKATOS, E. M.; MARCONI, M. de A. Fundamentos de metodologia científica. 7.ed. São Paulo: Atlas, 2010.

MUMFORD, L. A cidade na história. 1ํv. Ed. Itatiaia Ltda. Belo Horizonte. 1965.

SINAY, M.C.F. O Transporte de Carga Urbana e os Fatores que Inibem sua Eficiência. Workshop sobre Tendências de Distribuição em Rotas Urbanas, FIAT Automóveis, Betim, MG, 2003. 
VASCONCELLOS, E.A. Mobilidade urbana e cidadania. São Paulo: SENAC, 1996.

VASCONCELLOS, E. de A. Transporte e meio ambiente: conceito e informações para análise de impactos. São Paulo, Annablume, 2002.

Vaz, J.C; Santoro, P. 2009. Cartilha mobilidade urbana é desenvolvimento urbano! 2005. http//www.polis.org.br/publicacoes_interno.asp?codigo=194

VILELA, L. De O.; PENNISI, R.; ARANTES, T.; RODRIGUES, W.F. Transporte Urbano de Cargas: reflexões à luz da geografia dos transportes .Universidade Federal de Uberlândia (UFU). 2003. 